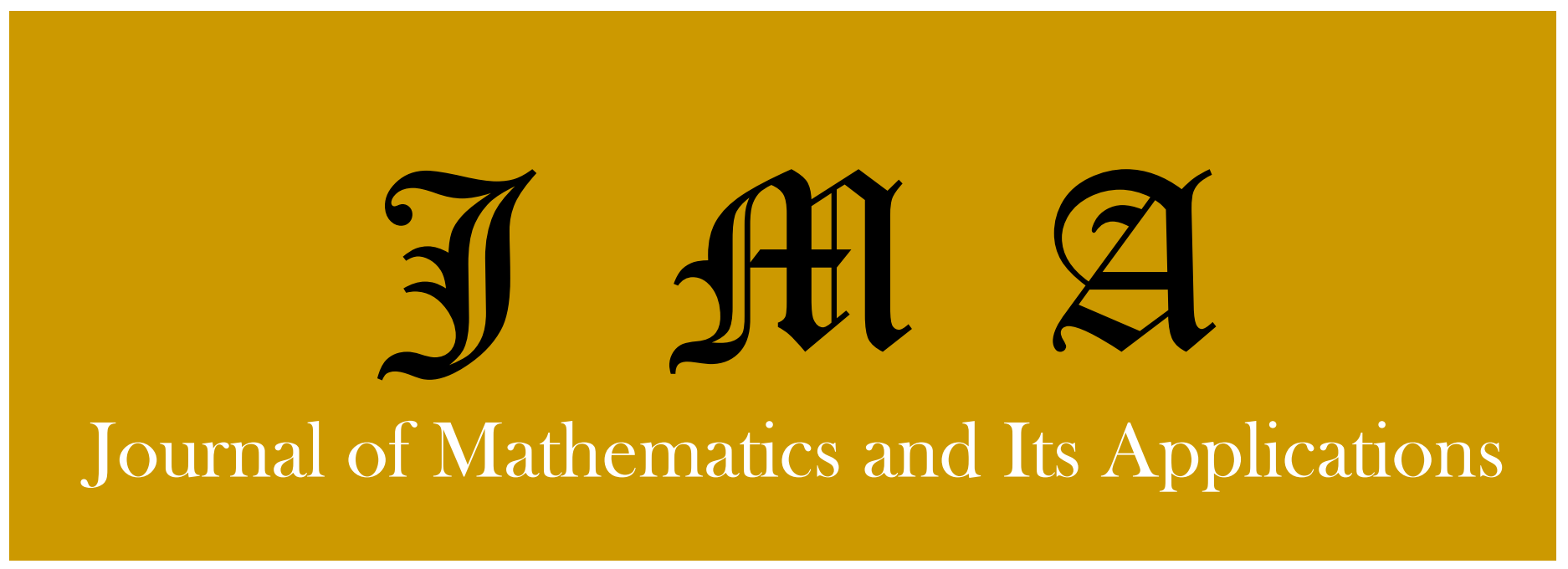

Volume 14, No. 2

\section{December 2015}

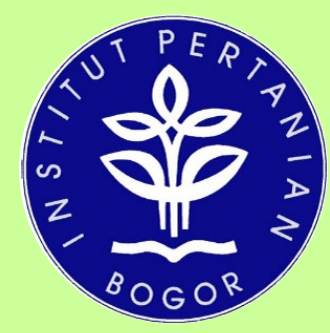

Department of Mathematics FMIPA - Institut Pertanian Bogor

JIn. Meranti, Kampus IPB Dramaga - Bogor

Phone/Fax: (0251) 8625276

E-mail: math@ipb.ac.id

jma.mathipb@gmail.com
Aplikasi Metode Transformasi Diferensial pada Sistem Persamaan Diferensial Biasa

E. Khatizah, P. T. Karima, dan D. I. Astuti

Penyelesaian Masalah Syarat Batas Persamaan Diferensial Biasa dalam Software $R$ dengan Menggunakan Bvpsolve W. Erliana, A. D. Garnadi, S. Nurdiati, dan M. T. Julianto

Pemodelan Frekuensi Petir di Bogor Menggunakan Pendekatan Logika Fuzzy

S. Nurdiati, E. Khatizah, dan N. Rosdiyana

Model Stokastik Penyebaran Penyakit Demam Berdarah di Kota Depok

H. Sumarno, P. Sianturi, A. Kusnanto, dan Siswadi

Penjadwalan Kegiatan Perkuliahan Menggunakan Goal Programming: Studi Kasus di Program Studi S1 Matematika FMIPA IPB

Ruhiyat, F. Hanum, dan R. A. Permana

Pemanfaatan Sumber Daya Alam Terbarukan dalam Model Sewa Ekonomi

F. Hanum, E. H. Nugrahani, dan S. Susanti 


\title{
$\mathfrak{I} \mathfrak{A t A}$
}

Journal of Mathematics and Its Applications

\author{
Editor In Chief \\ I Wayan Mangku, Institut Pertanian Bogor
}

Executive Editor

Windiani Erliana, Institut Pertanian Bogor

Managing Editor

M. Tito Julianto, Institut Pertanian Bogor

Editorial Boards

Alhadi Bustamam Universitas Indonesia

Amril Aman

Institut Pertanian Bogor

Fahren Bukhari

Institut Pertanian Bogor

I Gusti Putu Purnaba

Institut Pertanian Bogor

Kiki Arianti Sugeng Universitas Indonesia

Paian Sianturi

Institut Pertanian Bogor

Saib Suwilo

Universitas Sumatera Utara

Siswadi

Subchan

Sugi Guritman

Institut Pertanian Bogor

Suhartono

Tulus

Institut Teknologi Sepuluh Nopember

Institut Pertanian Bogor

Institut Teknologi Sepuluh Nopember

Universitas Sumatera Utara

Department of Matematics

FMIPA - Institut Pertanian Bogor

Jalan Meranti, Kampus IPB Dramaga Bogor

Phone/Fax: (0251) 8625276

Email: math@ipb.ac.id,jma.mathipb@gmail.com

Website: www.math.ipb.ac.id/ojs

$\mathfrak{I} \mathfrak{A} \mathfrak{A}$ is published twice in a year, in July and December. Editor receives original research papers and critical survey articles in all area of mathematics. In preparing the manuscript, please follow the author guideline (attached on the back cover). 


\section{GUIDELINES FOR AUTHORS}

$\mathfrak{I} \mathfrak{A} \mathfrak{A} \mathfrak{A}$ is published twice in a year, in July and December and managed by Department of Mathematics, Institut Pertanian Bogor. Editor receives original research papers and critical survey articles in all area of mathematics. Article can be written in English or Indonesian. Article will be reviewed by editor using some criteria. Those are originality, significancy, technical strength, written presentation, and relevance to the journal. Author will be given for revising based on recommendation from reviewer/editorial boards. Manuscript could be submitted to:

\section{Department of Mathematics \\ FMIPA - Institut Pertanian Bogor \\ Jalan Meranti, Kampus IPB Dramaga Bogor \\ Phone/Fax: (0251) 8625276 \\ Email: math@ipb.ac.id, jma.mathipb@gmail.com}

Article is written using microsoft word, A4 paper, one column, Times New Roman font (14 size for title and 12 size for body text), single spacing. Upper/bottom/right margin is $3 \mathrm{~cm}$ and left margin is $4 \mathrm{~cm}$ (mirrored margin). No more than 20 pages.

Abstract is written in English or Indonesian, no more than 250 words. Keywords: 3-5 words.

Acknowledgment is written at the end of the paper before references.

References should be listed in alphabetical order according to the surnames of the authors at the end of the paper. The following reference style should be used:

[1] Brown RL. 1997. Introduction to the Mathematics of Demography. $3^{\text {rd }}$ Ed. Winsted: Actec Publications.

[2] Guritman S, Hooweg F, Simonis J. 2001. The Degree of Functions and Weights in Linear Codes. Discrete Applied Mathematics. 111(1): 87-102.

For specific details, please download $\mathfrak{I} A \mathfrak{A}\{$ template in the website www.math.ipb.ac.id/ojs. 


\section{$\mathfrak{I} \mathfrak{A} \mathfrak{A} \mathfrak{A}$}

Journal of Mathematics and Its Applications

Vol. 14, No. 2, December 2015

Aplikasi Metode Transformasi Diferensial pada Sistem Persamaan Diferensial Biasa

E. Khatizah, P. T. Karima, dan D. I. Astuti

Penyelesaian Masalah Syarat Batas Persamaan Diferensial Biasa dalam Software $R$ dengan Menggunakan Bvpsolve

W. Erliana, A. D. Garnadi, S. Nurdiati, dan M. T. Julianto

Pemodelan Frekuensi Petir di Bogor Menggunakan Pendekatan Logika Fuzzy

S. Nurdiati, E. Khatizah, dan N. Rosdiyana

Model Stokastik Penyebaran Penyakit Demam Berdarah di Kota Depok H. Sumarno, P. Sianturi, A. Kusnanto, dan Siswadi

Penjadwalan Kegiatan Perkuliahan Menggunakan Goal Programming: Studi Kasus di Program Studi S1 Matematika FMIPA IPB

Ruhiyat, F. Hanum, dan R. A. Permana

Pemanfaatan Sumber Daya Alam Terbarukan dalam Model Sewa Ekonomi 


\title{
APLIKASI METODE TRANSFORMASI DIFERENSIAL PADA SISTEM PERSAMAAN DIFERENSIAL BIASA
}

\author{
E. KHATIZAH ${ }^{1}$, P. T. KARIMA ${ }^{2}$, D. I. ASTUTI ${ }^{2}$
}

\begin{abstract}
Abstrak
Metode transformasi diferensial merupakan salah satu metode pendekatan analitik yang cukup sederhana dan efektif dalam menyelesaikan sistem persamaan diferensial biasa linear dan tak linear. Pada penelitian ini, metode transformasi diferensial diterapkan untuk menentukan penyelesaian model Romeo-Juliet sebagai wakil sistem linear dan model Lotka-Volterra yang mewakili sistem tak linear. Menggunakan perbandingan dengan metode analitik dan metode numerik, hasil penelitian menunjukkan bahwa metode transformasi diferensial cukup akurat untuk selang di sekitar waktu awal $(t=0)$. Akan tetapi metode ini kurang akurat ketika selang waktu semakin meningkat. Dengan demikian, metode transformasi diferensial sangat cocok untuk mengamati perilaku variabel pada suatu model dalam jangka waktu yang relatif pendek.
\end{abstract}

Kata Kunci: metode transformasi diferensial, model Romeo-Juliet, model Lotka-Volterra.

\section{PENDAHULUAN}

Pencarian penyelesaian sistem persamaan diferensial dalam sebuah model menjadi penting untuk memenuhi tujuan tertentu. Sistem persamaan diferensial biasa linear umumnya dapat diselesaikan menggunakan metode analitik atau langsung seperti metode Laplace. Namun, untuk sistem persamaan diferensial biasa taklinear, penyelesaian secara analitik tidak mudah dilakukan. Beberapa metode numerik seperti metode Runge Kutta dapat diaplikasikan untuk memperoleh penyelesaian secara numerik atau penyelesaian dalam bentuk tabel [2]. Selain metode numerik tersebut, dapat pula digunakan metode iteratif yang menghasilkan suatu pendekatan penyelesaian analitik yang berupa sebuah fungsi.

Pada tahun 1986, Zhou memperkenalkan suatu metode yang dapat diterapkan untuk menyelesaikan persamaan diferensial baik linear maupun taklinear, yaitu metode transformasi diferensial. Metode yang menghasilkan pendekatan untuk penyelesaian analitik ini awalnya digunakan untuk menyelesaikan permasalahan nilai awal yang linear dan taklinear pada analisis sirkuit listrik [5]. Metode ini membangun sebuah teknik numerik semi-analitik dengan ide dasar deret Taylor untuk menghasilkan penyelesaian persamaan diferensial dalam bentuk polinom.

Pada penelitian ini, metode transformasi diferensial akan digunakan untuk menyelesaikan sistem persamaan diferensial biasa baik linear maupun tak linear.

\footnotetext{
${ }^{1}$ Departemen Matematika, Fakultas Ilmu Matematika dan Pengetahuan Alam, Jalan Meranti Kampus IPB Dramaga Bogor, 16680.

${ }^{2}$ Mahasiswa S1, Departemen Matematika, Fakultas Ilmu Matematika dan Pengetahuan Alam, Jalan Meranti Kampus IPB Dramaga Bogor, 16680.
} 
Untuk sistem persamaan diferensial linear akan diambil model Romeo-Juliet sebagai contoh kasus. Sedangkan untuk contoh kasus penyelesaian sistem persamaan diferensial tak linear akan diambil model mangsa pemangsa LotkaVolterra. Pengambilan kedua model yang berasal dari permasalahan di alam nyata ini sangat berguna untuk keselarasan interpretasi penyelesaian model. Selanjutnya, keakuratan metode transformasi diferensial akan diamati dengan cara membandingkannya dengan penyelesaian analitik (untuk sistem linear) dan penyelesaian numerik (untuk sistem tak linear).

\section{METODE TRANSFORMASI DIFERENSIAL}

Transformasi diferensial merupakan suatu langkah iteratif untuk memperoleh penyelesaian analitik deret Taylor dari persamaan diferensial. Definisi dasar dari transformasi diferensial untuk fungsi yang memiliki turunan pada setiap titik di persekitaran domain $D$ sebagai berikut:

$$
U(k)=\frac{1}{k !}\left[\frac{d^{k} u(x)}{d x^{k}}\right]_{x=x_{0}}, k=0,1,2,3, \ldots
$$

dengan $u(x)$ merupakan fungsi asli dan $U(k)$ merupakan fungsi transformasi. Suatu fungsi $u$ di $x$ dapat dinyatakan dalam bentuk deret Taylor, yaitu

$$
u(x)=\sum_{k=0}^{\infty} \frac{1}{k !}\left[\frac{d^{k} u(x)}{d x^{k}}\right]_{x=x_{0}}\left(x-x_{0}\right)^{k} .
$$

Berdasarkan persamaan (1), maka persamaan (2) berubah menjadi

$$
u(x)=\sum_{k=0}^{\infty} U(k)\left(x-x_{0}\right)^{k} .
$$

Saat $x_{0}=0$, diperoleh

$$
u(x)=\sum_{k=0}^{\infty} U(k) x^{k}
$$

yang disebut sebagai invers transformasi diferensial.

Terdapat beberapa teorema yang menunjukkan sifat operasi dasar metode transformasi diferensial [1]. Adapun teorema-teorema tersebut adalah sebagai berikut.

\section{Teorema 1}

Jika $y(x)=g(x) \pm h(x)$, maka $Y(k)=G(k) \pm H(k)$. 


\section{Teorema 2}

Jika $y(x)=\alpha g(x)$, maka $Y(k)=\alpha G(k)$.

\section{Teorema 3}

Jika $y(x)=\frac{d g(x)}{d x}$, maka $Y(k)=(k+1) G(k+1)$.

\section{Teorema 4}

Jika $y(x)=\frac{d^{2} g(x)}{d x^{2}}$, maka $Y(k)=(k+1)(k+2) G(k+2)$.

\section{Teorema 5}

$\operatorname{Jika} y(x)=\frac{d^{m} g(x)}{d x^{m}}$, maka $Y(k)=(k+1)(k+2) \ldots(k+m) G(k+m)$.

\section{Teorema 6}

Jika $y(x)=1$, maka $Y(k)=\delta(k)=\left\{\begin{array}{l}1, k=0 \\ 0, k \neq 0\end{array}\right\}$.

\section{Teorema 7}

$\operatorname{Jika} y(x)=x$, maka $Y(k)=\delta(k-1)=\left\{\begin{array}{l}1, k=1 \\ 0, k \neq 1\end{array}\right\}$.

\section{Teorema 8}

Jika $y(x)=x^{m}$, maka $Y(k)=\delta(k-m)=\left\{\begin{array}{c}1, k=m \\ 0, k \neq m\end{array}\right\}$.

\section{Teorema 9}

Jika $y(x)=g(x) h(x)$, maka $Y(k)=\sum_{m=0}^{k} G(m) H(k-m)$.

\section{Teorema 10}

Jika $y(x)=e^{(\lambda x)}$, maka $Y(k)=\frac{\lambda^{k}}{k !}$, dengan $\lambda$ adalah konstanta.

\section{METODE TRANSFORMASI DIFERENSIAL PADA SISTEM PERSAMAAN DIFERENSIAL BIASA LINEAR}

Model yang digunakan untuk mewakili sistem persamaan diferensial linear adalah model Romeo - Juliet. Strogatz memodelkan hubungan cinta antara Romeo dan Juliet menggunakan dua variabel, yaitu $R(t)$ sebagai akumulasi cinta Romeo untuk Juliet pada waktu $t$ dan $J(t)$ sebagai akumulasi cinta Juliet terhadap Romeo (atau benci jika konstantanya negatif) pada waktu $t$ [3]. Model sederhana linear dari cinta Romeo dan Juliet tersebut adalah sebagai berikut.

$$
\frac{d R}{d t}=a R+b J
$$




$$
\frac{d J}{d t}=c R+d J
$$

Nilai $a$ dan $b$ menentukan "gaya romantis" Romeo, sedangkan nilai $c$ dan $d$ menentukan gaya Juliet. Selanjutnya, dipilih nilai $a>0$ dan $b>0$ yang menunjukkan perasaan cinta Romeo akan selalu bertambah terhadap Juliet. Di sisi lain, dipilih nilai $c<0$ dan $d>0$ yang menunjukkan jika semakin besar interaksi yang diberikan oleh Romeo maka perasaan cinta Juliet akan semakin berkurang terhadap Romeo.

Mengambil nilai $a=0.6, b=0.8, c=-0.01, d=0.4$, diperoleh sistem persamaan diferensial

$$
\begin{aligned}
& \frac{d R}{d t}=0.6 R+0.8 J \\
& \frac{d J}{d t}=-0.01 R+0.4 J
\end{aligned}
$$

dengan memilih nilai $\boldsymbol{R}(\mathbf{0})=\mathbf{1 0 0}$ dan $\boldsymbol{J}(\mathbf{0})=\mathbf{5 0}$.

Sebagaimana umumnya sistem persamaan diferensial linear, penyelesaian Model Romeo-Juliet ini dapat ditentukan secara analitik menggunakan transformasi Laplace. Penyelesaian analitik tersebut dinyatakan dalam dua persamaan berikut.

$$
\begin{aligned}
& J(t)=(25-30 \sqrt{5}) e^{\frac{1}{50}(25+\sqrt{5}) t}+(30 \sqrt{5}+25) e^{-\frac{1}{50}(25+\sqrt{5}) t} \\
& R(t)=-10(25-30 \sqrt{5}) e^{\frac{1}{50}(25+\sqrt{5}) t}-2(25-30 \sqrt{5}) e^{\frac{1}{50}(25+\sqrt{5}) t} \sqrt{5} \\
& \quad-10(30 \sqrt{5}+25) e^{-\frac{1}{50}(-25+\sqrt{5}) t}+2(30 \sqrt{5}+25) e^{-\frac{1}{50}(-25+\sqrt{5}) t} \sqrt{5}
\end{aligned}
$$

Menggunakan metode transformasi diferensial, sistem persamaan (4) dapat dituliskan menjadi

$$
\begin{aligned}
R(k+1) & =\frac{1}{(k+1)}[0.6 R(k)+0.8 J(k)], \\
J(k+1) & =\frac{1}{(k+1)}[-0.01 R(k)+0.4 J(k)] .
\end{aligned}
$$

Substitusi nilai awal $R(0)$ dan $J(0)$ akan menghasilkan koefisien polinom hasil invers transformasi sesuai persamaan (3) sehingga diperoleh polinom berikut

$$
\begin{gathered}
R(t)=100+100 t+37.6 t^{2}+8.4 t^{3}+1.322933 t^{4}+\cdots \\
J(t)=50+19 t+3.36 t^{2}+0.314667 t^{3}+0.010467 t^{4}+\cdots
\end{gathered}
$$


Polinom inilah yang merupakan pendekatan penyelesaian analitik sistem persamaan (4).

\section{METODE TRANSFORMASI DIFERENSIAL PADA SISTEM PERSAMAAN DIFERENSIAL TAK LINEAR}

Model yang digunakan untuk mewakili sistem persamaan diferensial tak linear adalah model dasar mangsa pemangsa Lotka-Volterra. Model Lotka-Volterra menggambarkan sistem interaksi dua spesies yang diperkenalkan secara terpisah oleh Alfred J. Lotka dan Vito Volterra sekitar tahun 1920. Interaksi yang memberikan pengaruh terhadap banyaknya populasi dua spesies tersebut adalah rantai makanan. Asumsi utama yang digunakan dalam model ini adalah hanya terdapat dua spesies yaitu mangsa (prey) dan pemangsa (predator), populasi mangsa akan menurun pada saat terjadinya interaksi mangsa dengan pemangsa dan populasi pemangsa akan meningkat pada saat terjadinya interaksi mangsa dan pemangsa [4].

Secara matematis, model Lotka-Volterra dinyatakan sebagai berikut:

$$
\begin{aligned}
& \frac{d x(t)}{d t}=x(t)(a-b y(t)) \\
& \frac{d y(t)}{d t}=-y(t)(c-d x(t))
\end{aligned}
$$

dengan $x, y>0$ dan konstanta $a, b, c, d>0$, serta

$x$ : banyaknya populasi mangsa pada waktu $t$ (satuan populasi),

$y$ : banyaknya populasi pemangsa pada waktu $t$ (satuan populasi),

$a$ : laju pertumbuhan populasi mangsa (satuan 1/waktu),

$b$ : tingkat interaksi antara populasi mangsa dengan populasi pemangsa yang berpengaruh terhadap populasi mangsa (satuan 1/(populasi.waktu)),

$c$ : laju kematian alami populasi pemangsa (satuan 1/waktu),

$d$ : tingkat interaksi antara populasi mangsa dengan populasi pemangsa yang berpengaruh terhadap populasi pemangsa (satuan 1/(populasi.waktu)).

Selanjutnya, metode transformasi diferensial akan diaplikasikan untuk menentukan pendekatan penyelesaian analitik model Lotka-Volterra. Penyelesaian yang diperoleh akan menunjukkan banyaknya populasi mangsa dan pemangsa setelah terjadi interaksi di antara keduanya pada waktu tertentu.

Sebagaimana pada sistem persamaan linear, sistem persamaan (8) dapat dituliskan menjadi dua fungsi transformasi sesuai Definisi 4, Teorema 1, Teorema 2, Teorema 3, dan Teorema 9. Diperoleh

$$
X(k+1)=\frac{1}{(k+1)}\left[a X(k)-b \sum_{m=0}^{k} X(m) Y(k-m)\right]
$$




$$
Y(k+1)=\frac{1}{(k+1)}\left[-c Y(k)+d \sum_{m=0}^{k} X(m) Y(k-m)\right] .
$$

Mengambil nilai awal $x(0)=14, y(0)=18$, dan nilai parameter $a=1$, $b=1, c=0.1$, dan $d=1$, diperoleh pendekatan penyelesaian analitik sistem persamaan (8) berupa polinom berikut.

$$
\begin{aligned}
& x(t)=\sum_{k=0}^{\infty} X(k) t^{k}=14-238 t+271.6 t^{2}+20191.31333 t^{3}+\cdots \\
& y(t)=\sum_{k=0}^{\infty} Y(k) t^{k}=18+250.2 t-403.11 t^{2}-20087.343 t^{3}+\cdots
\end{aligned}
$$

\section{AKURASI METODE TRANSFORMASI DIFERENSIAL}

Untuk menilai keakuratan metode transformasi diferensial, akan dibandingkan antara grafik penyelesaian analitik hasil transformasi Laplace dan grafik pendekatan penyelesaian analitik hasil metode transformasi diferensial pada model Romeo-Juliet. Selanjutnya, akan dibandingkan pula antara grafik pendekatan penyelesaian analitik hasil metode transformasi diferensial dan grafik penyelesaian built in Mathematica untuk model Lotka-Volterra. Kedua perbandingan grafik tersebut dapat dilihat pada Gambar 1 dan Gambar 2.

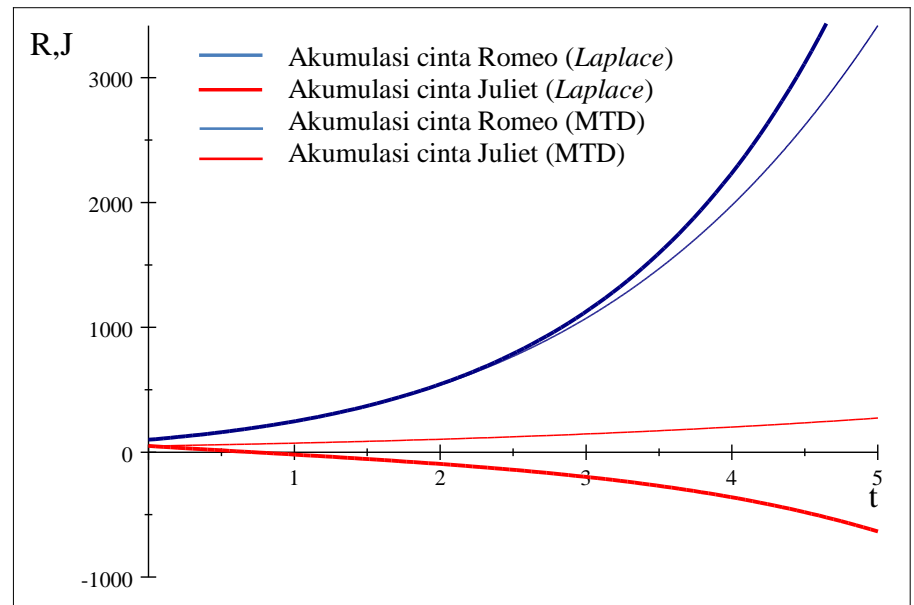

Gambar 1 Grafik penyelesaian Model Romeo-Juliet dengan metode transformasi diferensial (MTD) dan transformasi Laplace

Berdasarkan Gambar 1, untuk selang waktu mula-mula atau ketika $t$ di sekitar $t=0$, grafik penyelesaian analitik (transformasi Laplace) hampir berimpit dengan grafik pendekatan penyelesaian analitik yang diperoleh menggunakan metode transformasi diferensial. Akan tetapi, seiring meningkatnya $t$ terdapat penyimpangan cukup lebar yang mengindikasikan adanya galat. Penyimpangan ini cukup signifikan untuk grafik yang menyatakan akumulasi cinta Juliet, $J(t)$. Bahkan perilaku grafik hasil plot persamaan (6) ini berbeda nyata dengan grafik 
penyelesaian analitiknya. Menurut grafik penyelesaian analitik, akumulasi cinta Juliet semakin menurun bahkan bernilai negatif. Hal ini berbeda dengan grafik hasil metode transformasi diferensial yang monoton naik. Di sisi lain, grafik yang diperoleh dari plot persamaan (7) memiliki perilaku yang mirip dengan penyelesaian analitiknya, yaitu monoton naik atau memiliki arti bahwa akumulasi cinta Romeo terus meningkat seiring bertambahnya $t$.

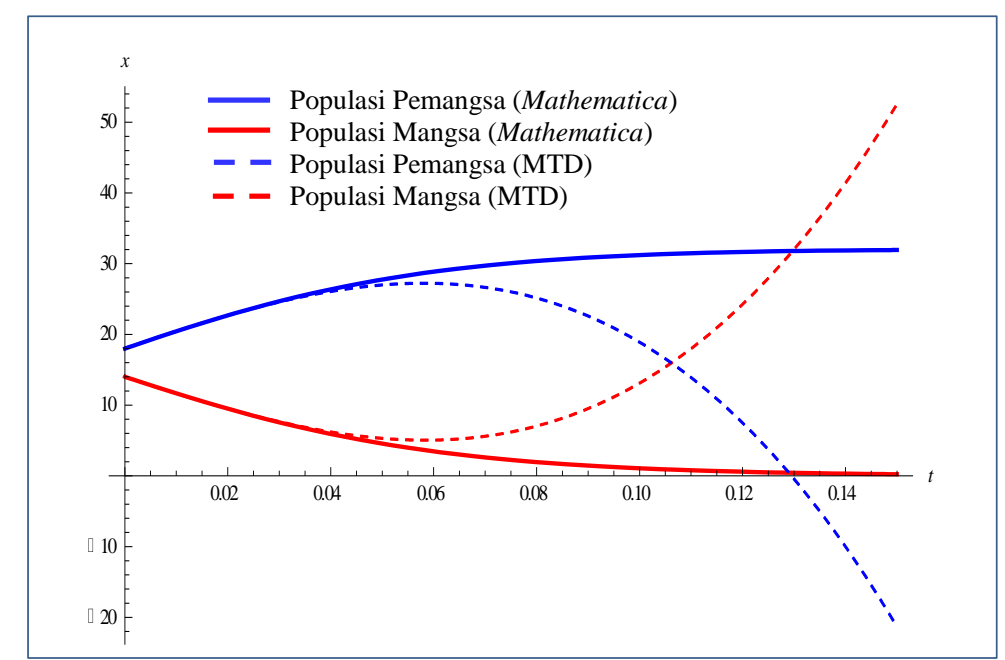

Gambar 2 Grafik penyelesaian Model Lotka-Volterra dengan metode transformasi diferensial (MTD) dan metode numerik built-in Mathematica

Berdasarkan Gambar 2, untuk selang waktu mula-mula atau ketika $t$ di sekitar $t=0$, grafik penyelesaian analitik (transformasi Laplace) hampir berimpit dengan grafik pendekatan penyelesaian analitik yang diperoleh menggunakan metode transformasi diferensial. Akan tetapi, seiring meningkatnya $t$ terdapat penyimpangan cukup lebar yang mengindikasikan adanya galat. Hal ini serupa dengan kasus model Romeo-Juliet. Akan tetapi, penyimpangan pada model LotkaVolterra cukup signifikan baik untuk grafik yang menyatakan populasi pemangsa, maupun grafik yang menyatakan populasi mangsa. Hal ini mengindikasikan adanya galat yang relatif besar. Meskipun demikian, grafik persamaan (9) dan persamaan (10) ini memenuhi asumsi model Lotka-Volterra, yaitu populasi mangsa akan menurun pada saat terjadinya interaksi mangsa dengan pemangsa dan populasi pemangsa akan meningkat pada saat terjadinya interaksi mangsa dan pemangsa.

\section{SIMPULAN}

Metode transformasi diferensial dapat digunakan untuk menyelesaikan sistem persamaan diferensial biasa linear dan tak linear. Metode ini menghasilkan polinom yang merupakan pendekatan penyelesaian analitik dengan proses yang cukup 
sederhana. Dengan model Romeo-Juliet sebagai wakil sistem linear dan model Lotka-Volterra sebagai wakil sistem tak linear, metode trasnformasi diferensial dapat diamati keakuratannya. Mengambil perbandingan dengan metode analitik dan metode numerik dapat disimpulkan bahwa metode transformasi diferensial cukup akurat untuk selang waktu di sekitar $t=0$. Akan tetapi, metode ini kurang akurat untuk selang waktu yang semakin meningkat. Dengan demikian, metode transformasi diferensial sangat cocok digunakan untuk mengamati perilaku variabel pada suatu model dalam jangka waktu yang relatif pendek.

\section{DAFTAR PUSTAKA}

[1] Batiha B. 2015. The solution of the prey and predator problem by differential transformation method. International Journal of Basic and Applied Sciences. 4(1): 36-43. doi: 10.14419/ijbas.v4i1.4034.

[2] Munir R. 2003. Metode Numerik. Bandung (ID): Informatika.

[3] Sprott JC. Dynamical Models of Love. Nonlinear Dynamics, Psychology, and Life Sciences, Vol. 8, No. 3, July, 2004

[4] Virginia Polytechnic Institute and State University. 1996. Quantitative Population Ecology. Virginia (US): VPISU. [diunduh 2015 Mar]. Tersedia pada: https://home.comcast.net/ sharov/PopEcol/lec10/lotka.html.

[5] Yesilce Y. Differential transform method for free vibration analysis of a moving beam. International Journal of Structural Engineering and Mechanics. 35(5): 645-658. doi: 10.12989/sem.2010.35.5.645. 